\title{
Electrocardiographic Abnormalities in Multisystem Inflammatory Syndrome Related to COVID-19
}

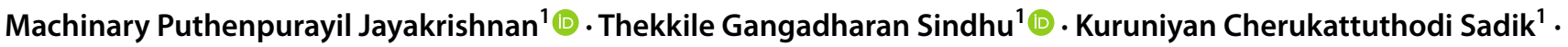 \\ Vellani Thamunni Ajithkumar ${ }^{1}$. Gopalan Nair Rajesh ${ }^{2}$
}

Received: 28 December 2021 / Accepted: 8 February 2022 / Published online: 8 March 2022

(c) The Author(s), under exclusive licence to Dr. K C Chaudhuri Foundation 2022

To the Editor: Multisystem inflammatory syndrome related to COVID-19 infection in children (MIS-C) manifests as fever and features of generalized inflammation. Reports on electrocardiographic (ECG) abnormalities in MIS-C are scarce with no studies published in India.

We analyzed the serial ECGs of children admitted in the PICU with the diagnosis of MIS-C during the period March to August 2021. Children with PICU stay of less than $1 \mathrm{~d}$ and those with no serial daily ECGs were excluded.

A total of 42 children in the age group 1-12 y were admitted with MIS-C during the study period; of which, 37 were eligible for inclusion in the study.

Abnormalities in ECG were found in the majority of children $(33,89 \%)$ and the predominant changes included ectopic supraventricular rhythms $(21,57 \%)$, T-wave abnormalities like abnormal T-wave axis and global T-wave inversion $(15,40.5 \%)$ and prolonged QT interval $(25,67.6 \%)$. The mean duration of fever before the onset of these changes was $7 \mathrm{~d}$. Ectopic supraventricular rhythms included junctional rhythm $(13,35 \%)$, wandering atrial pacemaker $(4,10.8 \%)$, and coronary sinus rhythm $(3,8.1 \%)$. Sinus tachycardia (19, $51 \%)$, sinus bradycardia $(1,3 \%)$, and transient first degree atrioventricular block $(3,8 \%)$ were the other changes.

One child had transient episodes of self reverting wide complex tachycardia, suggestive of possible ventricular tachycardia. There was no statistically significant association between any of the ECG changes and length of PICU stay, shock, left ventricular dysfunction, elevated troponin I, or elevated NT-Pro BNP.

Machinary Puthenpurayil Jayakrishnan

mpjk2019@gmail.com

1 Department of Pediatrics, Government Medical College, Kozhikode, Kerala 673008, India

2 Department of Cardiology, Government Medical College, Kozhikode, Kerala, India
We observed abnormalities in ECGs in the majority of children with MIS-C, and unlike other reports [1-4], there was a high incidence of ectopic supraventricular rhythms in this sample. These changes might help in making the diagnosis of MIS-C with atypical presentation, and also potentially indicate the need for more intense monitoring in these children.

\section{Declarations}

Conflict of Interest None.

\section{References}

1. Regan W, O'Byrne L, Stewart K, et al. Electrocardiographic changes in children with multisystem inflammation associated with COVID-19: associated with coronavirus disease 2019. J Pediatr. 2021;234:27-32.e2.

2. Ramcharan T, Nolan O, Lai CY, et al. Paediatric inflammatory multisystem syndrome: temporally associated with SARS-CoV-2 (PIMSTS): cardiac features, management and short-term outcomes at a UK tertiary paediatric hospital. Pediatr Cardiol. 2020;41:1391-401.

3. Dionne A, Mah DY, Son MBF, et al. Atrioventricular block in children with multisystem inflammatory syndrome. Pediatrics. 2020;146:e2020009704.

4. Choi NH, Fremed M, Starc T, et al. MIS-C and cardiac conduction abnormalities. Pediatrics. 2020;146:e2020009738.

Publisher's Note Springer Nature remains neutral with regard to jurisdictional claims in published maps and institutional affiliations. 